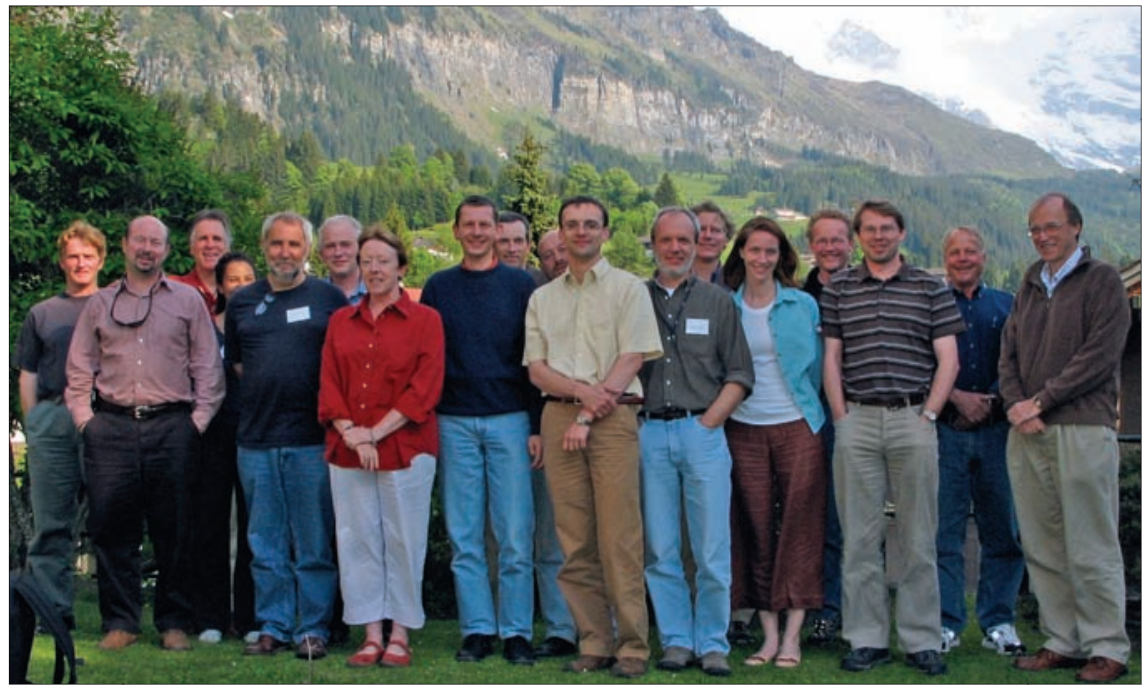

Figure 1: The group of participants in front of the Wengen mountains.

patterns of surface temperature, atmospheric circulation, precipitation and drought. The group also noted the importance of considering dynamical mechanisms such as the El Niño/Southern Oscillation (ENSO) in interpreting past climate changes. The recent PAGES and CLIVAR initiatives on past regional variability in South America and the Mediterranean region follow this principle (see PAGES News 2005/1, 2005/2 and 2005/3).

The group recognized that additional effort is needed in the archiving of paleoclimate data and associated metadata. They also agreed on the importance of encouraging scientists to provide not just the proxy data and climate reconstructions, but as much information as possible about random and systematic error and uncertainty. The latter information is crucial, for example, in comparisons of paleoclimate evidence with model simulation results. The participants agreed that progress in climate modeling approaches is also crucial to a better understanding of past climate variability, and to the assessment of current and future anthropogenic impacts on climate. To this end, the workshop participants agreed to plan a community-wide "paleoclimate re- construction challenge" in the near future (see Program News, page xx, this issue). This challenge will build on the theme of model intercomparison, using synthetically derived "pseudoproxy" test datasets derived from climate models as a test of methods used in paleoclimate reconstruction, similar in many respects to last year's "EPICA Challenge" initiative (see e.g. EOS, No. 38, 2005). A second project addressing proxy data uncertainties and data archiving is also being planned.

The four-day workshop in the unique setting of the snow-covered Bernese Alps provided a stimulating setting for informal discussions, setting the stage for productive activities in the months and years ahead. A synthesis publication on the state of the art of late Holocene climate variability will be published by the workshop participants. Follow-up activities are currently being planned.

\section{ACKNOWLEDGEMENTS}

The workshop was funded by the Electric Power Research Institute (EPRI), PAGES,

Swiss NCCR-Climate and CLIVAR.

Christoph Kull ${ }^{1}$, Keith Briffa, Phil Jones, Michael Mann and Heinz Wanner 'PAGES Office, Bern, Switzerland kull@pages.unibe.ch

\title{
ICDP workshop PASAD0: Deep drilling at Laguna Potrok Aike, a maar lake in southern Argentina
}

Río Gallegos, Argentina; 15-19 March 2006

Patagonia is subjected to shifts in polar and mid-latitude winds, pressure fields and precipitation regimes, as well as to variations related to $\mathrm{EI} \mathrm{Ni-}$ ño Southern Oscillation (ENSO) and the Antarctic Oscillation (AO). Therefore, environmental and climatic reconstructions have the potential to provide unique records of variations in the hydrological cycle, changes in aeolian dust deposition, and consequences and frequencies of volcanic activities. Since 2001, crater lakes of the Pali Aike Volcanic Field (southernmost Patagonia, Argentina) have been studied in the framework of the interdisciplinary project "South American Lake Sediment Archives and Modelling" (SALSA) funded by the German Climate Research Program (DEKLIM) and carried out in close cooperation with Argentine scientists (PAGES News 12/2, 9-11). On-site monitoring and multidisciplinary reconstructions based on sediment cores from the maar lake Laguna Potrok Aike have formed the basis for environmental and climatic reconstructions on decadal up to millennial time scales. Located $52^{\circ} \mathrm{S}$, the lake received dust and volcanic ash from Patagonia and the Andean volcanic chain, which are distributed not only across South America but also blown over the South Atlantic and onto Antarctica. Thus, isotopic and aerosol tracers could be used to link these different areas, making not only inter-site but also inter-archive correlations available. Such data will advance hemispheric reconstructions of climate variability and proxy-model comparisons to better understand climate forcing factors. First results are promising but coring ended around $16 \mathrm{cal} \mathrm{ka} \mathrm{BP}$, due to technical restrictions of the available coring device.

With additional funding from the Priority Programme "ICDP" of the German Research Foundation (DFG), it was possible to carry out deep seismic surveys, which revealed $>150 \mathrm{~m}$ of lacustrine sediments underlain by $>350$ $\mathrm{m}$ of volcano-clastic deposits. As the maar formation occurred at 


\section{Workshop Reports}

$770 \pm 220 \mathrm{ka}$, seismic data suggest that lacustrine deposits may cover up to seven glacial cycles. This calls for a much larger scientific endeavor that can only be accomplished within the framework of the International Continental Scientific Drilling Program (ICDP). Thus, the research initiative "Potrok Aike Maar Lake Sediment Archive Drilling Project" (PASADO) was developed, with the goal to get the GLAD800 coring system to Patagonia.

The four-day ICDP PASADO workshop, consisting of 46 talks organized into 10 sessions, was convened in the Conference Hall at the Complejo Cultural Santa Cruz in Río Gallegos, Argentina from 15-19 March 2006, bringing together 52 participants from 11 countries (Fig. 1).

The first two sessions introduced participants to the study area. Attendees were impressed with the data presented and felt that Laguna Potrok Aike should be recommended as an appropriate target for future ICDP deep drilling because it is not only a unique site for terrestrial climate reconstruction in the southern hemisphere but also for investigation into the formation of a relatively young mid-Pleistocene phreatomagmatic crater. A fieldtrip during the workshop presented an overview of the lake and the surrounding catchment area from a prominent basalt escarpment, and focused on technical and logistical issues, as well as on volcanic evidence and records of

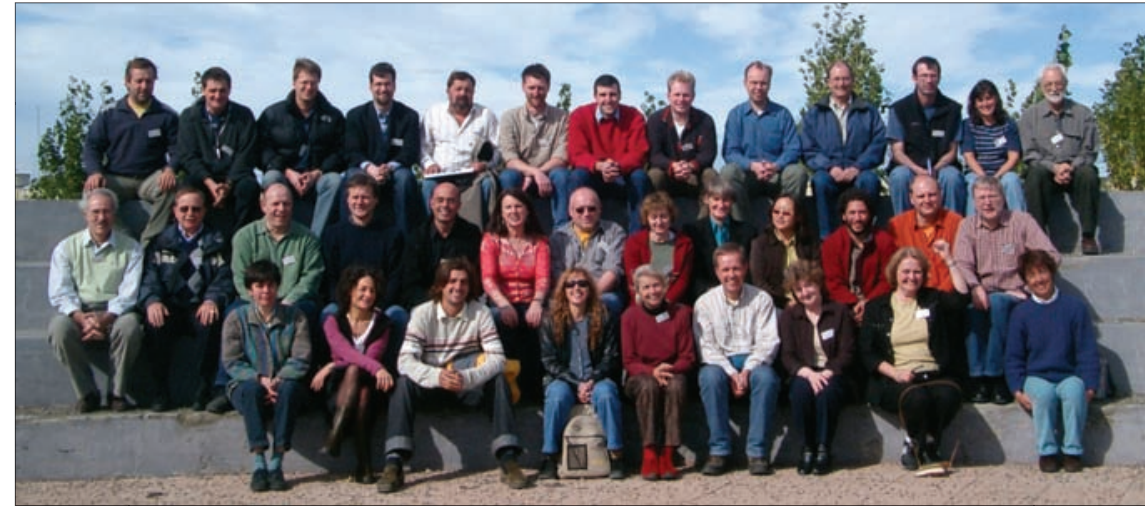

Figure 1: Participants of the PASADO workshop in Río Gallegos.

environmental change in the field. The day ended with an "asado", a famous Argentine-style barbeque, on the premises of the INTA field station Potrok Aike.

The concluding day was devoted to break-out groups on four major topics related to technical aspects of scientific drilling and on volcanological, inorganic and organic aspects of sediment core analysis. During a final plenary discussion, all the ideas and suggestions were pooled.

The ICDP PASADO workshop proved to be very successful, both in terms of scientific collaboration, as well as technical and logistical issues. Participants actively finetuned analytical strategies, focused on improving cooperation and coordination between scientific groups, and developed the timeframe and outline for the full ICDP deep drilling proposal. The science plan that was established already serves as a basis for international cooperation, and several proposals have been developed and submitted to national funding agencies in support of PASADO. However, although the first milestone has passed, there are still plenty of opportunities to expand the scientific community involved through international collaboration.

The scientific program, list of participants, abstracts of presentations and excursion guide were published as Terra Nostra 1/2006. Further information can be obtained from www. salsa.uni-bremen.de.

\section{ACKNOWLeDGEMENTS}

The PASADO workshop was organized by the team of GEOPOLAR (Institute of Geography, University of Bremen) and hosted by the Universidad Nacional de la Patagonia Austral (Río Gallegos). It was supported logistically by the Government of Santa Cruz and the Instituto Nacional de Tecnologia Agropecuaria (INTA), and financially by ICDP.

Bernd Zolitschka ${ }^{1}$, Hugo Corbella, Nora Maidana and Christian 0 HLendorf

'University of Bremen, Germany; zoli@uni-bremen.de

\section{Climate change: A multi-dimensional challenge}

\section{Lund, SWeden; 26-28 0ctober 2005}

As part of the British Council's program International Networking for Young Scientists (INYS) a BritishSwedish-Danish workshop was organized by the Swedish Meteorological and Hydrological Institute, the Geological Survey of Denmark and Greenland, the Climate Research Unit at the University of East Anglia, and the Hadley Centre (part of the Meteorological Office). A principal aim of the workshop, which brought together 19 young scientists, was to promote interaction between people who generate reconstructions of past climates from paleo-data, those who work with instrumental time series and those who work on climate modeling. Six keynote lectures were given and these included topics such as projections of climate change over the next few decades, the usefulness of global climate models, the added value of regional modeling, and the nature of the geological data that form the basis of a reconstruction of a widespread cooling event at approx. 8200 years ago.

A highlight of the workshop was Professor Bert Bolin's keynote lecture "To use scientific knowledge on climate change in politics." Bert was a founding Chair of the Intergovernmental Panel on Climate Change (IPCC) and was instrumental in the initial formulation of the World Climate Research Programme (WCRP). In his 80th year, he captivated a full audience with his personal and often revealing insight into how the scientific community must relay their concerns about climate change to the public and politicians. His message was clear; there is a great deal of knowledge on climate and, notwithstanding the remaining uncertainties (Fig. 1), urgent measures must 